\title{
TYPES OF PERSONALITY MOTIVATION STRUCTURE OF WOMEN WHO ARE ACQUIRING HIGHER EDUCATION IN PSYCHOLOGY
}

\author{
TETIANA PARTYKO \\ partyko.tet@gmail.com \\ Ivan Franko Lviv National University
}

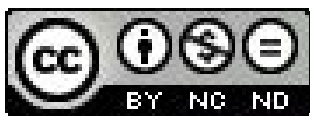

\begin{abstract}
The article deals with the results of empirical research on the types of personality motivation structure of women who are acquiring higher education in psychology. Two types have been singled out: expressive and impulsive. The expressive type comprises two components: ideal motivation aimed at life necessities, general activity and social utility, and real motivation aimed at comfort, social status and communication. In the structure of the impulsive type there are three components: real motivation aimed at life necessities, social status, general activity and social utility; real motivation aimed at communication and comfort; creativity motivation aimed at self-development and creative activity. Women belonging to the expressive type of personality motivation structure have more positive self-attitude and a higher level of psychological well-being than women belonging to the impulsive type.
\end{abstract}

Key words: motivation structure, expressive type, impulsive type, self-attitude, psychological well-being, women, education in psychology.

Contemporary circumstances of social development create new landmarks for the professional education of specialists in psychology. Under the circumstances when education in psychology becomes available to people of different ages, it is obvious that we need a new strategy for education which takes into consideration the motivation sphere of the learners.

Motivational compatibility/incompatibility with the future professional activity is an indispensable precondition for forming professional competence and social maturity of a person. Playing a motivational role, it affects axiological and orientational spheres of personality and, in the long run, professional decisions. That is the reason why the personality motivation structure of a future psychologist may become an innovational resource of society.

The issue of the motivational sphere of students in higher education institutions is traditionally viewed in the context of pedagogical psychology. The issues connected with the types of academic motives, their structure and hierarchy, dynamics, specific features of professional orientation, stages of formation etc. have been researched.

It has been discovered that student self-perfecting stimulates intrinsic motivation and evokes extrinsic motivation which is expressed in a wish to realize one's talents, achieve professional success, and creativity. It has been discovered that 
the most significant motives for students education are the motives of personality development and orientation in new knowledge (Badmayeva, 2004, p. 280).

Studying the motives for educational activities of adults in the period of professional retraining, Svetlana Ye. Chirkina specified the importance of cognitive motives, motives for achievement, affiliation and dominance (Chirkina, 2005, p. 18). Natalia Ts. Badmayeva described the divergences in the motivation of educational activities depending on the chosen profession. The future psychologists put professional motives in first position, communicative - in the second, creative - in the third (Badmayeva, 2004, p. 280).

Oleksandr S. Kocharian, Yevhenia V. Frolova and Vitaliy M. Pavlenko have discovered the following. The final-year students of both technical and humanitarian specialities demonstrated, first of all, decrease in personality motivation structure of successful students. Successful students continue to study mechanically, because a personal myth contributes to this. Secondly, unsuccessful students are characterized by a more differential system of motives which the authors of the research explain by the fact that during their final year they want to make up for the lost during all previous years of studies. Such a structure in the motivational sphere is observed with successful first-year students. It is assumed that the development of the motivational sphere of unsuccessful students is retarded because they realize the significance of studying only during the final years of studies. Thirdly, the researchers explain the specificities of motivation during the final years of studies by the motivational exhaustion of the successful students personality. Motivational exhaustion is more explicit with the students of technical specialities. It is expressed in the form of emotional and semantic exhaustion. The authors of the research conclude that when studying at a higher education institution the initial motivation which was present during the first years of studies becomes exhausted, and new academic and professional motivation is not formed. It testifies to the devaluation of adulthood and, correspondingly, the higher education (Kocharian, Frolova, \& Pavlenko, 2011, p. 40).

The present research is aimed at identifying the types of personality motivation structure of women acquiring higher education in psychology. Both real and ideal displays of motivation has been analysed. Attention has been paid to the specific features of self-attitude and psychological well-being of women. Due to the fact that psychological education in Ukraine is largely feminized $(85-90 \%$ of students acquiring education in psychology are women), the personality motivation structure of women has been researched.

\section{RESEARCH PROCEDURE}

142 women acquiring complete higher education majoring in psychology participated in the empirical research. The age of the women under research is from 16 to $47,76 \%$ of them are adolescents, $22,6 \%$ are in the period of early adulthood and $1,4 \%$ - of late adulthood. Among the students $32,4 \%$ are first-year students, $26,8 \%$ are second-year students, $19,7 \%$ are third-year students and $21,1 \%$ are fifth- 
year students (post-graduate education). 28\% of those surveyed spent their childhood in villages, $17 \%$ - in town-type villages and $55 \%$ - in cities. At the time of the research $14,1 \%$ of respondents were residents of villages, 7,7\% - of town-type villages and $78,2 \%$ - of cities. $2,8 \%$ said their health was bad, $43 \%$ - average and $54,2 \%$ - good. $3,5 \%$ of women thought their financial condition was bad, 55,7\% average, $40,8 \%$ - good.

Thus, the vast majority of those surveyed are adolescents who spent their childhood in the city and at the time of the research were residents of cities, have good health and average financial condition.

In order to study the personality motivation structure we have used the methods of Vadim E. Milman, which diagnose the motivational and emotional profiles of the personality (Milman, 1990, p. 253). In order to study the psychological specificities of women we have used the methods of studying self-attitude by Vladimir V. Stolin and Serhiy R. Panteleyev (Romanova, 2009, pp. 360-366) and the Ryff scales of psychological well-being as adapted by Tetiana D. Shevelkova and Pavel P. Fesenko (Istratova, Eksakusto, 2012, pp. 93-103).

The data has been analysed depending on the type of respondents personality motivation structure. The reliability of the achieved results was verified with the help of the following mathematical and statistical analyses: cluster (kmeans method on those surveyed), discriminatory (Wilks'Lambda), contrastive (Student's T-tests with $\mathrm{p}<0,05)$, correlational - according to r-Pearsona (with $\mathrm{p}<0,05$ ). The procedure of factorial analysis (with $>, 50$ ) consisted in determining key factors resulting from the procedure Varimax normalized for each of the groups.

\section{TYPES OF PERSONALITY MOTIVATION STRUCTURE OF STUDENTS MAJORING IN PSYCHOLOGY}

In order to identify personality motivation structure of women acquiring education in psychology, clusterisation of data has been conducted. The scales of motivational and emotional profile of V. Milman methods have been used for this purpose. Two clusters have been singled out. The correctness of classification for the first cluster is $96,77 \%$, for the second - 97,50\%. Discriminatory analysis showed that first of all clustering took place according to such scales of motivational profile as social status, ideal overall life motivation, creativity, social utility, communication, and such scales of emotional profile as sthenic and asthenic types of emotional response $(\lambda=0,311 ; F=7,134 ; p=0,000)$.

In order to conduct a more detailed analysis of quantitative and qualitative factors of the singled out clusters, motivational profiles for each group were created (fig. 1). According to V. Milman, the profile of the students belonging to the first cluster is close to the expressive type, while the students of the second cluster have the impulsive type of motivational profile. 


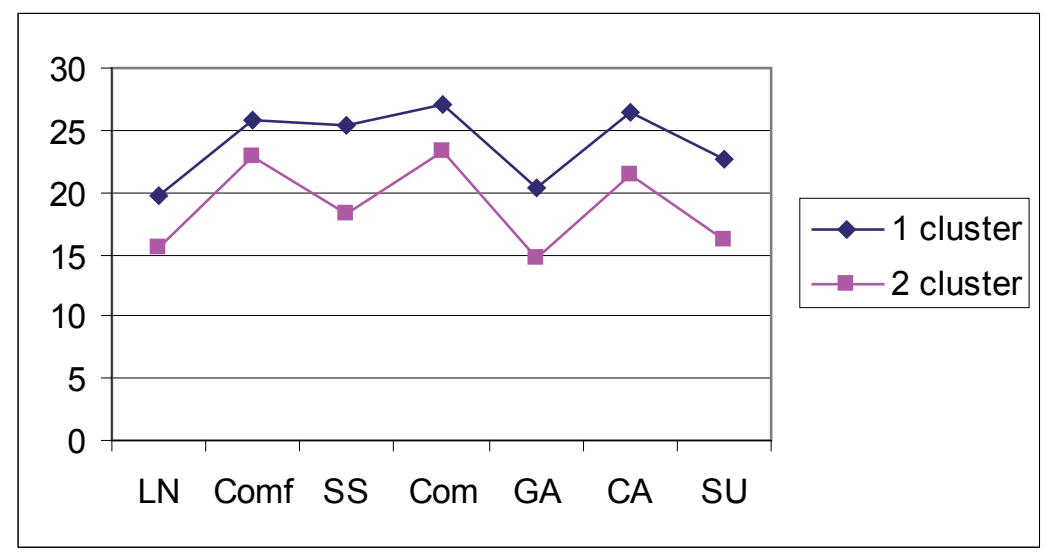

Figure 1. Motivational profile of students belonging to the first and second clusters. Source: Author.

(LN - life necessities, Comf - comfort, SS - social status, Com - communication, GA - general activity, $\mathrm{CA}$ - creative activity, $\mathrm{SU}$ - social utility)

In the expressive type group of motivation structure such motives of personality support as social status and comfort dominate, and such motive of personality development dominates as creative activity and the need for communication. This type comprises $43,7 \%$ of the surveyed students, the majority of whom $(69,4 \%)$ are unemployed, they spent their childhood in the city $(59,7 \%)$ and at the time of the research they are city residents $(80,6 \%)$. They consider their health to be good $(62,9 \%)$, and financial condition to be average $(50 \%)$ or good $(48,4 \%)$. If we compare the years of studies, 30,6\% of students belonging to the expressive type are first-year students, $22,6 \%$ - second-year, 17,8\% - third-year and 29\% - fifth-year students.

A sudden drop of profile line with three distinct peaks connected with comfort, communication and creative activity is typical of the impulsive type of student personality motivation structure. This profile testifies to the considerable differentiation of various motivational factors in the general structure of personality. The impulsive type comprises $56,3 \%$ of the surveyed students. Mainly these are unemployed persons $(83,8 \%)$, almost half of them spent their childhood in the city $(51,3 \%)$ and at present the majority of them also live in the city $(76,3 \%)$. Less than half of the students $(47,5 \%)$ consider their health to be good. $60 \%$ consider their financial condition to be average and 35\% - good. 33,8\% of the students belonging to the impulsive type are first-year students, 30\% - second-year, 21,2\% - thirdyear and $15 \%$ - fifth-year students.

The contrast of these two profiles has shown that the students belonging to the expressive type have more distinct overall life and working (academic) motivation than the students of the impulsive type ( $\mathrm{p}$ within 0,002 to 0,000 ). They pay more attention to life necessities, living comfort and their social status; they are more prone to communication, general and creative activity, and also they are more motivated for useful social activity (fig. 1). 


\section{SPECIFICITIES OF SELF-ATTITUDE AND PSYCHOLOGICAL WELL-BEING OF STUDENTS BELONGING TO THE EXPRESSIVE TYPE OF PERSONALITY MOTIVATION STRUCTURE}

Students belonging to the expressive type of personality motivation structure have a higher opinion about themselves and are more self-confident $(t=3,327$ when $p=0,001)$, they think they have higher ability to self-regulation $(t=2,183$ when $p=0,03$ ), they are more likely to think that they are respected and liked by others $(t=3,442$ when $p=0,000)$, they appreciate their own personality and the richness of their inner world more, and also acknowledge the value of their «ego» for others $(t=4,696$ when $p=0,000)$ in comparison with the students of the impulsive type. They are also characterised by the absolute acceptance of their traits $(t=2,494$ when $p=0,013)$. Having more positive general self-attitude, they are less likely to change their self-image $(t=3,665$ when $p=0,000)$, less often think about their inner problems and difficulties $(t=-2,901$ when $p=0,004)$ and more rarely resort to self-accusation $(t=-2,438$ when $p=0,016)$ than women of the impulsive type.

The students of the expressive type are more trusting in their relations with other people, more empathic, communicative and compliant $(t=4,037$ when $\mathrm{p}=0,000$ ), they control the situation more competently and use their abilities more efficiently creating the conditions for achieving their goals and satisfying their needs $(t=5,386$ when $p=0,000)$, they better feel their life direction $(t=5,171$ when $p=0,000$ ) than the students of the impulsive type. They also assess their past more positively and accept their own positive and negative traits $(t=3,598$ when $\mathrm{p}=0,000)$.

A six-factor model has been designed which highlights the role of self-attitude and psychological well-being for the expressive type of students personality motivation structure. The model explains $59,92 \%$ of the general data dispersion. The remaining dispersions are caused by accidental influences which are not discussed in the present model. The first factor Psychological well-being (Prp.Totl $12,82 \%$, Expl.Var 3,85) comprises the following indicators of a person's psychological well-being: positive relations with others $(0,718)$, autonomy $(0,685)$, control of the environment $(0,657)$, personality growth $(0,676)$, goal in life $(0,654)$, self-acceptance $(0,593)$, as well as an indicator of self-attitude - secrecy $(0,628)$. The second factor Ideal motivation (Prp.Totl 11,08\%, Expl.Var 3,32) includes ideal overall life motivation $(0,615)$, ideal academic (working) motives $(0,614)$, the motive of life necessities $(0,711)$, general activity motive $(0,875)$ and social utility motive $(0,684)$. The third factor Real motivation (Prp.Totl 9,8\%, Expl.Var 2,96) testifies to the real overall life $(0,738)$ and academic (working) motivation $(0,600)$, the importance of communication motives $(0,771)$, social status $(0,692)$ and comfort $(0,675)$. The fourth factor Self-respect (Prp.Totl 11,51\%, Expl.Var 3,45) describes the person's self-love $(0,614)$, self-acceptance $(0,571)$, inner conflict $(-0,786)$, self-accusation $(-0,787)$ and the asthenic type of emotional response $(-0,653)$. The fifth factor "Sthenity" (Prp.Totl 7,79\%, Expl.Var 2,34) includes the sthenic type of emotional response $(0,825)$, the emotional component of motivation $(0,773)$ and frustration component of motivation (0,552). The final sixth factor Self-acceptance (Prp.Totl 6,92\%, Expl. 
Var 2,08$)$ combined self-acceptance $(0,661)$, inherent worth $(0,616)$ and a person's alter ego $(0,605)$.

The harmonious combination of ideal and real motivation is typical of the expressive type of students personality motivation structure. Ideal motivation is more aimed at the problems connected with the person's life necessities, their general activity and orientation towards socially beneficial activity. It is more characteristic of those women who think that their personality traits and activities are respected, liked, approved and understood by others $(\mathrm{r}=0,285)$ and they have a liking for themselves $(\mathrm{r}=-0,284)$. The ideal academic (working) motivation is more typical of the older students $(0,328)$ who are in their final years of studies $(\mathrm{r}=0,285)$, they are employed $(\mathrm{r}=0,271)$ and more prone to the asthenic type of emotional response $(\mathrm{r}=0,396)$,

Real life motivation for the students of this type of motivation structure is aimed at securing their social status, comfort and successful communication. It is more typical of the younger persons $(\mathrm{r}=-0,353)$ who are in their first years of studies $(\mathrm{r}=-0,424)$, unemployed $(\mathrm{r}=-0,316)$, they have positive self-attitude $(\mathrm{r}=0,256)$, clear life goals $(\mathrm{r}=0,281)$ and good health $(\mathrm{r}=0,305)$. Real academic (working) motivation is more characteristic of reserved people $(\mathrm{r}=0,291)$ with positive self-attitude $(r=0,272)$ and self-acceptance $(r=0,304)$, and also with a distinct life orientation $(\mathrm{r}=0,382)$.

Distinct motivation of communication and creative activity of the students belonging to the expressive type of personality motivation structure is connected with the following psychological specificities. Communication motive in motivation structure is more typical of the younger students $(\mathrm{r}=-0,549)$ who are in their first years of studies $(\mathrm{r}=-0,465)$, unemployed $(\mathrm{r}=-0,412)$ and have good health $(\mathrm{r}=0,272)$. Communication motive is closely connected with the wish for comfort $(\mathrm{r}=0,646)$, social status $(\mathrm{r}=0,342)$ and real overall life motivation $(\mathrm{r}=0,517 ; \mathrm{r}=0,295)$. The creative activity motive of the students belonging to the expressive profile correlates with real life motives $(\mathrm{r}=0,362)$, their wish for self-consistency and independence $(\mathrm{r}=0,299)$, personality growth $(\mathrm{r}=0,294)$. This motive is more characteristic of unemployed students $(\mathrm{r}=-0,269)$ and those students who spent their childhood in the city $(\mathrm{r}=0,275)$.

\section{SPECIFICITIES OF SELF-ATTITUDE AND PSYCHOLOGICAL WELL-BEING OF THE STUDENTS BELONGING TO THE IMPULSIVE TYPE OF PERSONALITY MOTIVATION STRUCTURE}

Persons belonging to the impulsive type of personality motivation structure do not have such a high opinion of themselves as those belonging to the expressive type. They are less self-confident and set a low value on their ability for self-regulation. The students of this group are not always sure that strangers like them, they appreciate less the richness of their inner world and not always absolutely accept their negative traits. However, they are a lot more open for personality changes and inner reflections, specification of their self-image in comparison with the expressive type. They more often accuse themselves of different failures, at the 
same time they are more frank and sincere than the students of the expressive type of personality motivation structure. They are less communicative and compliant, they are not that competent when dealing with the situation and use their abilities less efficiently for achieving their goals. They feel their life orientation worse and do not assess it as positively as the persons of the expressive type.

A six-factor model has been designed which highlights the role of self-attitude and psychological well-being for the impulsive type of students personality motivation structure. The model explains $58,88 \%$ of the general data dispersion (the remaining dispersions are not discussed in the present model). The first factor Psychological well-being (Prp.Totl 17,61\%, Expl.Var 5,28) comprised the following parts of a person's psychological well-being: positive relations with others $(0,623)$, control of the environment $(0,722)$, goal in life $(0,725)$ and self-acceptance $(0,812)$. This factor also includes indicators of a person's self-attitude: secrecy $(0,590)$, self-confidence $(0,555)$, self-regulation $(0,571)$, a person's alter ego $(0,605)$, a person's inner conflict $(-0,663)$, self-accusation $(-0,512)$. The second factor Real academic (working) motivation (Prp.Totl 9,97\%, Expl.Var 2,99) combined real academic (working) motivation of women $(0,694)$, motives for life necessities $(0,679)$, social status $(0,527)$, general activity $(0,753)$ and social utility $(0,505)$. The third factor Personality growth (Prp.Totl 7,99\%, Expl.Var 2,39) consists of the indicator of a person's personality growth $(0,667)$, a person's self-love $(-0,593)$ and a creative activity motive $(0,693)$. The fourth factor Real overall life motivation (Prp.Totl 10,54\%, Expl.Var 3,16) shows a close connection of real overall life motivation of students $(0,678)$, communication motives $(0,789)$ and comfort $(0,693)$. The fifth factor Sthenic emotions (Prp.Totl $6,34 \%$, Expl.Var 1,90) includes the emotional part of women's motivation $(0,792)$ and the sthenic type of emotional response $(0,623)$. The sixth factor Frustration motivation (Prp.Totl 6,43\%, Expl.Var1,93) combines the frustration part of the students' motivation $(0,686)$ and their autonomy $(-0,621)$.

The factor structure of the impulsive type of students' motivation is connected with real motivation only. Their real academic (working) motivation is aimed at problems of life necessities, social status, general activity and socially beneficial activity. Real academic (working) motivation is more characteristic of self-confident students $(\mathrm{r}=0,279)$ who are convinced they can manage their life and have internal unity $(\mathrm{r}=0,278)$. They better control their activity and use their abilities more efficiently, as a result they achieve their goals $(\mathrm{r}=0,238)$ and have a goal in life $(\mathrm{r}=0,225)$. Real academic (working) motivation is more characteristic of wealthier students $(\mathrm{r}=0,242)$.

Real overall life motivation is more aimed at comfort and communication of students. It is more characteristic of those people who think they are liked and respected by others $(\mathrm{r}=0,410)$, have trusting relations with others, are empathic and compliant $(\mathrm{r}=0,447)$, have good health $(\mathrm{r}=0,268)$.

As it has been mentioned above, the most typical motives of students belonging to the impulsive type of personality motivation structure are the motives of comfort, communication and creative activity. A wish for comfort will grow with the need for communication $(r=0,593)$. The motive of comfort is more typical of unemployed students $(r=-0,263)$. A wish to acquire a higher social status grows 
with age $(r=0,224)$, year of studies $(r=0,232)$, it is directly connected with the motives of overall life necessities ( $\mathrm{r}=0,413)$, comfort $(\mathrm{r}=0,338)$, communication $(\mathrm{r}=0,281)$, general activity $(r=0,240)$ and social utility $(r=0,267)$, and it is higher with students who have good relations with others and are satisfied with them $(r=0,238)$. The creative activity motive of the students belonging to the impulsive type of personality motivation structure will increase on condition of increased significance of communication motive $(\mathrm{r}=0,251)$, the importance of personality growth $(\mathrm{r}=0,327)$ and recognition of how important one's personality is $(\mathrm{r}=0,236)$ and it will decrease with employed students $(r=-0,278)$ in their final years of studies $(r=-0,257)$ who are satisfied with their health $(\mathrm{r}=-0,244)$.

\section{CONCLUSIONS}

We have discovered two types of personality motivation structure of women acquiring higher education in psychology: expressive and impulsive. For the expressive type, the structure consists of two main components: ideal motivation aimed at personality support and growth and real motivation aimed at personality support. Ideal orientation forms the motives of life necessities, general activity and social utility and is more characteristic of older employed women. Real orientation forms the motives of comfort, social status and communication. It is characteristic of younger unemployed women acquiring higher education in psychology.

Women of the expressive type of personality motivation structure have higher overall life and academic (working) incentives in comparison with the impulsive type. They have more positive self-attitude, especially as far as the value of their personality for others and themselves is concerned. They pay more attention to their social status. Their self-image is more stable. Some aspects of their psychological well-being are more integrated and generally it is higher than with women of the impulsive type. This is largely achieved through self-confidence, moderate inner tension, vigour and independence of women.

There are less women of the expressive type than of the impulsive type. Among them there are more employed persons acquiring post-graduate education, they are more satisfied with their financial condition and health than women of the impulsive type.

The majority of women acquiring education in psychology have the impulsive type of personality motivation structure. It consists of three components: real motivation aimed at personality support and development; real motivation aimed at communicative aspect of comfort motive; motivation of creativity connected with self-development and creative activity. Real motivation orientation is more characteristic of women with better financial condition and better health. Ideal orientation was not included in personality motivation structure of women belonging to the impulsive type.

Women of the impulsive type of personality motivation structure have less positive self-attitude, they do not always consider they are valuable for themselves and others. Their self-image is less stable. Autonomy and personality growth are 
not integrated in their psychological well-being. At the same time psychological well-being is more closely connected with different aspects of positive self-attitude in comparison with the expressive type.

Further research of these issues may be connected with a more detailed study of personality motivation structure depending on the stage of education and gender.

\section{REFERENCES}

Badmayeva, N. Ts. (2004). Influence of the Motivational Factor on the Development of Mental Abilities. UlanUde: Publishing House VSGTU.

Kocharian, Ol. S, Frolova, Ye. V., \& Pavlenko, V. M. (2011). Motivation Structure of the Students' Academic Activities. Kharkiv: National Aerospace University named after M. Ye. Zhukovskiy.

Milman, V. E. (1990). Method of Studying of Personality Motivational Sphere. Psychodiagnostics Practical Guide. Psychodiagnostics of Motivation and Self-Regulation. Moscow: University Press.

Prodiblokh, N. Ye. (2004). Value-related and Motivational Peculiarities of a Student. Experience and Problems of Social and Economic Transformations under Conditions of Society Transformation: Region, City, Enterprise: Collection of Papers of the II International Scientific and Practical Conference. Penza: Publishing House RIO PGSHA. 191-194.

Psychodiagnostics. Personal and Professional Features. (2012). Author and compiler O. N., Istratova, T. V. Eksakusto. Rostov-on Don: Fenix.

Romanova, Ye. S. (2009). Psychodiagnostics. Second Edition. Saint-Petersburg: Peter.

Chirkina, S. Ye. (2005). Motives of Academic Activities as a Factor of Efficient Adult Training in the Period of Professional Retraining: PhD Author's abstract: 19.00.07. Kazan: Education Development Institute of the Tatarstan Republic. 